\title{
Participatory Journalism, Blurred Boundaries: Introducing Theoretical IS Frameworks to Re-orient Research Practices
}

\author{
Nora Martin \\ University of Technology - Sydney, Ultimo, Australia \\ nora.martineuts.edu.au
}

\begin{abstract}
Social media now plays a pivotal role in how broadcast media engages with their audiences. This paper contemplates the nature of our digital media culture, the diversity of actors involved and how the role of the journalist has evolved. The methodology includes examining the findings of a pilot research study investigating journalists' information practices in the digital realm. Two theoretical frameworks from the discipline of Information Science are introduced to re-orient research practices. The findings reveal digital journalism facilitates richer and more expansive storytelling, with connectivity between experts, journalists and the public. The author posits that the citizeninformant is reconceptualised in the news milieu.
\end{abstract}

Keywords: Digital journalism, News-story verification, Social media

\section{Introduction}

In the digital world, the nature of news has fundamentally changed. This paper explores the impact of converging technologies on journalism practice in an age of digital social media. The discussion draws on the findings of pilot research study investigating journalists' information practices in the digital realm [1] and explores the application of theoretical frameworks from Information Science to re-orient research practices. This voyage of discovery will assist in navigating the blurred boundaries of our journalistic terrain, thereby seeing it with new eyes.

\section{Research Methods}

Interviews are widely used for exploring the sense-making of social actors, drawing out the rhetorical construction of their experience and perspective [2]. In journalism research, interviews have been employed in studies on networked journalism $[3,4]$ and news-story verification $[5,6]$.

This paper explores digital media using a qualitative framework [2]. The research methodology includes examining the findings of a pilot research study on the effect of social media on journalists' information practices [1]. The findings were based on interviews with journalists employed in the Australian broadcast media sector. The 
researcher adopted a case study approach whereby in-depth interviews with nine semi-randomly selected participants were undertaken. ${ }^{1}$

The interviews were face-to-face, in informal settings where each participant worked. Qualitative semi-structured interviews using the Neutral Questioning technique [7] were conducted to ascertain how journalists verify and report on information originating in or reaching them via social media. Participants were asked in a general way for his/her views on how journalists discover, use and share information. This led to a discussion on how broadcast media professionals assess the credibility of new information and whether social media technologies are influencing the way journalists access and share information. These interviews were recorded with the consent of the participants.

No effort was made to define social media technologies, or any of the terms or phrases used during the interviews. This minimized bias from the researcher's thoughts or persuasions as much as possible. As the interviews were informal, each interview was more like a conversation. In this way, the researcher was able to elicit detailed answers from each participant. The interviews were transcribed in full, with the transcripts reviewed by the researcher to determine broad themes that suggested trends. Analysis was conducted on the data using Grounded Theory [8]. Participants were de-identified to ensure ethical practice.

\section{Theories}

\subsection{Theory of Information Poverty}

The Theory of Information Poverty [9] places information-seeking behavior within the framework of social norms in a bid to understand why individuals sometimes do not seek, ignore, or actively avoid information that could be useful. Chatman defines an impoverished information world as a dysfunctional one in which "a person is unwilling or unable to solve a critical worry or concern", in part because of their status as an insider or outsider [9]. Here, insiders are people who use their greater understanding of social norms to enhance their social roles, and outsiders are those who deviate from the norm. Chatman sees the insider-outsider conflict as the context for engagement in self-protective behaviors which influence how information is sought and used [10].

Chatman's characterisation of the insider-outsider conflict reflects the social status of so-called traditional journalists and their tech-savvy counterparts when it comes to technology. Journalists who do not use Twitter are regularly portrayed as falling short of the tech-savvy norm, concretising their status as outsiders [11]. For the 'traditional' reporter, a world which constantly privileges breaking news over investigative reporting could engender the deep distrust that Chatman suggests. It is possible that traditional journalists' acceptance or avoidance of technologies could be shaped by

${ }^{1}$ In the initial pilot research study, two in-depth, qualitative semi-structured interviews were undertaken [20]. For this follow-up research, seven in-depth interviews were conducted with semi-randomly selected broadcast media professionals to collect further qualitative data. 
the insider-outsider conflict. Chatman's theory therefore has valuable applications in studies of technology acceptance pertaining to journalism in a socially networked world.

\subsection{Suzanne M. Miller's Monitoring-and-Blunting Theory}

Monitoring-and-Blunting (M\&B) Theory seeks to explain people's informationseeking behavior during stressful situations. Miller suggests that, when faced with a stressful or aversive event, people differ in their preference for information [12]. 'Monitors' are people who seek information because 'knowing what is happening' helps to decrease their stress. 'Blunters' deal with unfavourable events by distracting themselves and avoiding information as a self-protective measure. M\&B theory provides insight into information seeking as a coping mechanism, acknowledging that each individual is unique in his/her desire for information [12]. In doing so, Miller emphasizes the inextricability of users from their situational contexts.

Miller's approach presents very worthwhile concepts and recommendations for media researchers. The investigation of affective factors as motivators for information behavior can be usefully adapted to research in digital media culture and provides a sound basis for a holistic exploration of journalists use (or non-use) of social networks such as Twitter. When faced with a threatening situation, a journalist can respond by focusing on the threatening information ('monitoring') using Twitter as a newsfeed or by avoiding threatening information ('blunting') by choosing not to engage with, or otherwise use this medium.

To date few studies have examined the differences between categories of journalists in relation to social media use [13]. There is a need for more research which recognises the significance of emotion in driving human interaction with technology. Similarly, Olsson believes "the growth of social media opens up ideal territory to explore issues of the role of affective discourses in emerging virtual social spaces" [14].

\section{Age of Participatory News}

The shift to tablets and smartphones for communication, news and entertainment has dramatically changed the media terrain. A recent Nielsen report reveals that $56 \%$ of Australians read a newspaper via digital devices every month [15].

When asked whether social media is influencing the way journalists access and share information, here is one particular viewpoint:

I'm a believer that it's a tool and it doesn't replace anything that's already there. It's another tool in your tool kit, it's like you bought a new spanner, you know, that's a different size. It is changing things, I'm not saying it's not... it's just another way of accessing things (Z2).

In relation to Twitter, one participant underscored the fact that only once a reputable news source is associated with a story is it seen as having authority and credibility. 
... something recently flashed up about Nairobi; that X number of people had been shot at, at that shopping centre in Nairobi, and the first flash came from someone whose name you don't recognise. But the minute you see a reputable news source, that news brand attaching their name to the story, that's when it becomes an important story to follow (A1).

The balance of power between news media and the audience has been irrevocably altered, with a power shift in the digital age from 'journalist as gatekeeper' to the citizen as editor. As Jarvis argues, "witnesses to events can now help report what they see and context and explanation can come from both journalists and the experts they quoted who can now also publish....I see that not as a competitive threat, but as a grand opportunity" [16].

\subsection{BLUNTERS - We Verify Now and Publish Later}

Verification is a routine part of journalistic information gathering activities. One participant, when discussing the use of Twitter, said:

So even though I might log onto Twitter regularly I won't pay much attention to individuals who are not attached to organisations which I respect. Individuals are just that, unless I can verify where they come from, where they are attached to and therefore how much weight I should give their opinions and thoughts (A1).

Equally, participants insisted that other motivations for conforming to this ideal ranged from the impact of an error on their credibility (A1, Z2, W6), on the reputation of their news brand (A1) or that of the journalistic profession as a whole (A1, Z2, $\mathrm{X} 4)$. As one participant maintains:

It's my reputation and also you owe it to the story I think, because if you get something wrong, of course you can get sued and stuff like that if there's defamation and all those legalities (Z2).

Another participant points out that working in a deadline driven situation means it is imperative not to waste time on sources that could be doubtful:

It's very important that I don't waste time ... reading information that could be from a questionable source, and that doesn't attribute its facts and statistics to any organisation or entity that I can then research further ... it's all about verifying the original source (A1).

Evidence based practice is often at the core of journalistic endeavours, with "information gathered according to rigorous principles and presented in the formats of conventional science" [17]. This aligns with the research by Shapiro et al. in their Canadian study [6]. Their findings reveal substantial diversity in verification strategies employed by journalists, often mirroring social scientific methods such as 'source triangulation.'

\subsection{MONITORS - We Publish Now and Correct Later}

Networked journalism has created numerous challenges, with concerns about sourcing, authenticity and fairness due to "looser editing standards that often exist with a digital first policy stressing speed over verification", often without effective 
front-end checks and balances [18]. Various participants stressed the importance of being accurate in the 24/7 news environment, making statements attesting to this professional norm.

When discussing how to assess the credibility of new information, as one put it:

... I mean look it's a trap for all of us too you know, the very famous truism about assume makes an ass of you and me and it's something as journalists' who are striving to be accurate and known for that, we fall into that trap every single day potentially if we don't check, and it's not assuming (A1).

One participant thought a recent news story was published in a certain masthead. As it turned out, the story was published on another date and in a different paper. This matter was resolved after contacting a news researcher:

... you have to check and triple-check everything, I assumed it was in a certain publication ... there's a lot swilling in your head, you have to be accurate in this game, you have to be one-hundred percent accurate (A1).

Another participant emphasized the importance of familiarizing oneself with a subject, prior to commencing more in-depth research:

The first basis is that you need to read and become informed on what you're trying to investigate, because that body of knowledge and knowing who the players are in that story is important... when you go to social media, that body of knowledge gives you a base to be able to go 'that doesn't sound right, that does sound right, that fits in here', and it helps you put the pieces together (Z2).

This stance is best exemplified by Participant D5's comment in relation to the 24/7 news environment, and how it is imperative to beat competitors to the punch:

... I'm not interested in being a reporter that stands back and waits. You've got to get in there first and beat the competitors. So, I'm all for breaking news. After all, that's the name of the game these days (D5).

\subsection{Witness as Citizen-Informant}

The evolving media landscape includes professional journalists in a plethora of 'social roles' [19]. Bloggers and user-generated content are inextricably woven into the news production process, the result being an incorporation of varied content, diversification of source material and multiplicity of actors. Today, eyewitnesses providing reports on news events is de rigueur. Yet, many of these actors do not consider themselves to be part of the citizen media contingent. In legal parlance, the definition of a citizeninformant is an ordinary citizen who has either been the victim of or witness to a crime and reports the pertinent facts to law enforcement officials. ${ }^{2}$ I therefore propose that this definition be reconceptualised in the news milieu. The ordinary citizen as an eyewitness who has reported on a news event but does not consider themselves to be

${ }^{2}$ Wallace v. State, 964 So.2d 722 (District Court of Appeal of Florida, 2007). In Wallace, Justice Wallace wrote 'Generally speaking, a citizen-informant is an ordinary citizen who has either been the victim of or a witness to a crime and who reports the pertinent facts to law enforcement officials,' Duhaime's Criminal Law Dictionary http://www.duhaime.org/LegalDictionary/C/CitizenInformant.asp $\mathrm{x}$ 
an amateur journalist, nor a part of the citizen media contingent, is henceforth known as a citizen-informant.

With the challenge for journalism to reinvent itself in the digital media environment comes the challenge for scholars to review their methods and question the durability of findings. Given the need to redirect the focus of research from the system to the user, a cross-disciplinary approach is a valuable way to inspire and generate new ideas and reflection [20].

\section{Conclusion}

This paper examined our participatory digital media culture, discussing the nature of this interaction, the multiplicity of actors and how the role of the journalist has evolved. The findings reveal that digital journalism facilitates richer story-telling, with connectivity between experts, journalists and the public. The author suggests that the citizen-informant is reconceptualised in the news milieu. Two theoretical frameworks from the discipline of Information Science were introduced in order to reorient research practices in participatory media. It is hoped that these theories will help redirect the focus of research in this field, from techno-centrism to the importance of considering social, situational and contextual factors.

\section{References}

1. Martin, N.: Information Verification in the Age of Digital Journalism. Paper presented at the Special Libraries Association Annual Conference (Vancouver: June 8-10, 2014)

https://www.sla.org/wp-

content/uploads/2014/07/Information-Verification.pdf

2. Bryman, A.: Social Research Methods. OUP, Oxford (2012)

3. Domingo, D., Le Cam, F.: Journalism in Dispersion. Digital Journalism 2 (3): 310-321 (2014) doi:10.1080/21670811.2014.897832

4. Lewis, J., Williams, A., Franklin, B., Thomas, J., Mosdell, N.: The quality and Independence of British Journalism. Project Report, MediaWise (2008) http: //www.mediawise.org.uk/wpcontent/uploads/2011/03/Quality-Independence-of-BritishJournalism.pdf

5. Godler, Y., Reich, Z.: How Journalists "Realize" Facts. Journalism Practice 7(6): 674689 (2013) doi:10.1080/17512786.2013.791067

6. Shapiro, I., Brin, C., Bédard-Brûlé, I., Mychajlowycz, K.: Verification as a Strategic Ritual. Journalism Practice 7(6): 1-18 (2013)

7. Dervin, B., Dewdney, P.: Neutral Questioning: A New Approach to the Reference Interview. Reference Quarterly 25(4): 506-513 (1986)

8. Glaser, B.G., Strauss, A. L.: Basics of Grounded Theory Analysis. Sociology Press, Mill Valley, CA (1967)

9. Chatman, E.A.: The Impoverished Life World of Outsiders. J. Am. Soc. Inf. Sci 47 (3): 193-206 (1996) 
10. Hersberger, J.A.: Are the Economically Poor Information Poor? Does the Digital Divide Affect the Homeless and Access to Information? Can. J. Inform. Lib. Sci. 27(3): 44-63 (2003)

11. Jericho, G.: The Rise of the Fifth Estate: Social Media and Blogging in Australian Politics. Scribe, Brunswick, Vic. (2012)

12. Baker, L.M.: Monitoring and Blunting. In: Theories of Information Behavior, edited by K.E. Fisher, S. Erdelez and L. McKechnie. Medford, NJ: Information Today (2005)

13. Hedman, U., Djerf-Pierre, M.: The Social Journalist. Digital Journalism 1(3): 368-385 (2013) doi:10.1080/21670811.2013.776804

14. Olsson, M.: Gently to Hear, Kindly to Judge: the Affective Information Practices of Theatre Professionals and Journalists. Information Research. 18(3) (2013) http://InformationR.net/ir/18-3/colis/paperc22.html

15. Nielsen Online Ratings.: IpsosMediaCT, people 14+ for the twelve months ending Dec 2013. emma ${ }^{\mathrm{TM}}$ (Enhanced Media Metrics Australia) (2013)

16. Jarvis, J.: For the Record | Comment. The Guardian. 1 December (2007) http://www.theguardian.com/commentisfree/2007/nov/30/forth erecord

17. Olsson, M.: Information Practices in Contemporary Cosmopolitan Civil Society. Cosmopolitan Civil Societies Journal 6(2): 79-93 (2014)

18. Steele, B.: Journalism Ethics Then And Now. In: McBride, K., Rosenstiel, T. (eds.) The New Ethics of Journalism, pp. vii - ix. CQ Press, Thousand Oaks, CA (2014)

19. Kovach, B., Rosenstiel, T. Blur: How to Know What's True in the Age of Information Overload. Bloomsbury, New York (2010)

20. Larsson, U. (ed.): Cultures of Creativity. Science History Publications (2006) 